\title{
Terminologia técnico-administrativa: os termos no espaço público brasileiro
}

RESUMO: Neste artigo, procura-se descrever princípios constitutivos de repertórios terminológicos divulgados pelos órgãos da administração pública do Brasil, como ministérios e agências reguladoras. Esses órgãos estão divulgando glossários com termos e respectivos conceitos de suas áreas de atuação. Mesmo fragmentadamente, o Brasil dispõe de uma terminologia "oficial". Interessa aos estudos de Terminologia identificar a constituição desses conjuntos terminológicos que compõem uma categoria de termos, aqui denominada de técnico-administrativa. Trata-se de uma constituição terminológica híbrida que é descrita e exemplificada. Conclui-se que a terminologia da administração pública constitui uma categoria de léxico especializado, com identidade própria, que se soma à dos domínios científicos, jurídicos e tecnológicos. Sua organização vincula-se aos princípios e missões dos órgãos administrativos do país.

Palavras-chave: Terminologia técnico-administrativa; hibridismo terminológico; glossários; administração pública.

\begin{abstract}
This paper has the objective of describing constitutive principles of terminological repertories divulged by public administration organs of Brazil, as ministries and regulation agencies. Those organs are divulging glossaries with terms and its respective concepts of their field of work. Though fragmentally, Brazil has an "official" terminology. It is of the interest to the Terminology studies to identify the constitution of those terminological sets that are part of a category of terms, here denominated "technical-administrative". It is about a hybrid terminological constitution that is described and exemplified. It is concluded that the terminology of public administration constitutes a category of specialized lexicon, with its own identity, that is summed to the scientific, legal and technological domains. Its organization links to the principle and missions of the country's administrative organs.
\end{abstract}

Keywords: Technical-administrative terminology; terminological hybridism; glossaries; public administration.

Universidade do Vale do Rio dos Sinos (UNISINOS). E-mail: mgkrieger@terra.com.br. 


\subsection{Introdução}

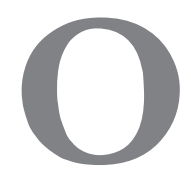

termo técnico-científico, objeto central de investigação da Ter-

minologia, caracteriza-se por assumir um caráter transdisciplinar ao se realizar na prática das comunicações especializadas dos mais diferentes campos do saber científico, jurídico, técnico, tecnológico entre tantos outros domínios profissionais. Tendo em vista que os termos representam nódulos cognitivos do conhecimento especializado, eles são elementos constitutivos e não acessórios da transmissão dos saberes. Daí por que não há comunicação especializada sem terminologia, e, consequentemente, a transdisciplinaridade terminológica é uma realidade linguística e semiótica incontestável.

À luz dessa onipresença dos termos em todos os domínios da vida profissional, Eugen Wüster (1996) concebeu a natureza transdisciplinar da terminologia, considerando que ela participa de todas "as matérias especializadas". Entendeu assim que todas essas matérias possuem e usam termos para representar seus conhecimentos. Por isso, afirmou ainda que sem terminologia não se faz ciência, nem se descreve uma técnica, nem se exerce uma profissão especializada.

É ainda em razão dessa visão abrangente que Wüster projetou os estudos terminológicos no âmbito da Linguística Aplicada, mas, sobretudo, como uma zona de fronteiras entre várias disciplinas, situada na convergência da Linguística, da Lógica, da Ontologia, das Ciências da Informação e das diferentes áreas do conhecimento científico e técnico. Nessa medida, atribui à Terminologia um caráter multidisciplinar (Wüster, 1998: 26). Essa composição múltipla é integrada, sempre e obrigatoriamente, por um domínio de saber especializado, componente que, em última análise, determina o estatuto terminológico de uma unidade lexical ou semiótica.

De um ponto de vista temático, muitos repertórios terminológicos atuais apresentam características multidisciplinares. É exemplo dessa situação a terminologia do Direito Ambiental, área que reúne um conjunto de saberes jurídicos e das ciências da natureza para equacionar e regulamentar as relações homem/natureza. O estabelecimento dos princípios e das condições sociais e jurídicas dessas relações é a finalidade última das leis e normas do Direito Ambiental. Esse fator é, por sua vez, determinante da unidade que marca a constituição do repertório terminológico dessa área jurídica.

$\mathrm{Na}$ realidade, a transdisciplinaridade e a multidisciplinaridade são fatores que incidem sobre a existência e a constituição das terminologias. Se o primeiro aspecto, pela sua abrangência, expressa um movimento linear já que 
cobre todos os saberes especializados, o segundo fator afeta a verticalidade constitutiva dos repertórios terminológicos, conferindo-lhes um caráter híbrido. A constituição híbrida está, em muito, relacionada à epistemologia das áreas do conhecimento, sobretudo, do mundo contemporâneo que tende a convocar diferentes saberes para ampliar e aprofundar objetos de análise.

De fato, atualmente, há muitos conjuntos terminológicos híbridos, não só pela natureza da área, que necessita de bases cognitivas oriundas de áreas distintas que contribuem para constituir um campo específico de saber; mas também em razão de finalidades pragmáticas que presidem a aplicação ou a operacionalização de conhecimentos especializados. Tais finalidades integram, por exemplo, as chamadas Ciências Sociais Aplicadas ${ }^{1}$, categoria integrada por áreas como Arquitetura, Direito, Economia e Administração, as quais representam o protótipo da investigação com fins direcionados ao mundo social. São especialidades que, em princípio, não se constituíram sobre a interdisciplinaridade, mas que a contém já que esses saberes não se resumem à construção pura do conhecimento, mas visam à sua aplicabilidade.

$\mathrm{Na}$ mesma linha de aplicabilidade, alinham-se domínios tradicionais da saúde como a Medicina e a Odontologia que, para cumprir seus fins de atendimento aos pacientes, também se valem de procedimentos, necessitam de instrumentais tecnológicos entre outros componentes que não expressam diretamente o conhecimento científico, muito embora seja este o fundamento primeiro de cada uma desses campos. Em decorrência, as ciências da saúde recorrem a instrumentos tecnológicos, o que lhes determina também repertórios terminológicos com aspectos multidisciplinares, embora neles predomine a dimensão científica, própria de suas identidades.

A Terminologia, de modo geral, tem tratado dos conjuntos terminológicos como blocos monolíticos, quer dizer, como constituídos de termos "naturais" de cada área do conhecimento, sem pensar na proveniência de outros domínios, nem na conjunção de saberes e práticas que se integram em campos específicos. É bem verdade que a inscrição de um termo "estrangeiro" numa área específica, quando ressemantizado, representa sua naturalização ao novo conjunto terminológico que o adota.

Tais questões ganham relevância porque atualmente, há inúmeros conjuntos terminológicos marcadamente híbridos, caso especial de áreas de gestão, que se estruturam sobre princípios, normas e procedimentos para regulamentar e administrar diversos ângulos e produtos necessários ao fun-

Trata-se de exemplos tomados à classificação das áreas do conhecimento de acordo com a categorização do CNPq. 
cionamento da sociedade contemporânea. Inclui-se aí, por exemplo, a gestão nos campos da economia, da saúde, da informação e do meio ambiente, campos cuja gestão pode estar afeta tanto à administração privada, quanto ao poder público. Neste último caso, a referência se faz à constituição da terminologia de organizações públicas de um país, conforme atestam, no Brasil, inúmeros glossários dos ministérios, agências reguladoras e secretarias de Estado, como adiante será descrito.

$\mathrm{Na}$ realidade, na gestão pública brasileira, vários órgãos governamentais estão inovando no sentido de sistematizar e divulgar suas terminologias como uma estratégia para facilitar as relações com os usuários de seus serviços, bem como divulgar os princípios e as normas da condução da vida pública, em especial, no plano dos serviços oferecidos ao cidadão. Trata-se, em última análise, de uma estratégia de gestão da informação que tem permitido que se configure hoje uma terminologia do espaço público brasileiro. Vale dizer, mesmo fragmentadamente, o Brasil dispõe de uma terminologia "oficial" (Krieger, 2009).

A constatação da existência da terminologia das organizações públicas do Brasil motiva a observação sobre sua composição, constituindo-se no propósito central deste artigo. Também outras motivações, específicas dos estudos sobre léxico especializado, impulsionam o interesse em lançar um olhar sobre essa terminologia, que tem se tornado cada vez mais divulgada e presente nas relações estado/sociedade brasileira:

a) a crença de que a reflexão sobre termos é sempre e ainda necessária para os estudos terminológicos, cujo objeto primeiro de investigação é o próprio termo;

b) a compreensão de que a aproximação aos termos pressupõe o reconhecimento de que há distintas categorias terminológicas, cujas especificidades constitutivas estão relacionadas à arquitetura cognitiva das áreas, mas também à dimensão pragmática, que orienta e ordena processos comunicativos que envolvem conhecimento especializado.

Vale dizer, há categorias distintas de saber especializado, caso, por exemplo, das ciências taxonômicas clássicas e do universo de conhecimento jurídico, cujos léxicos temáticos estão atrelados seja ao tipo de texto que, predominantemente, os veicula, seja à natureza da área e, indissociavelmente “às finalidades dos diferentes universos de discurso" (Krieger, 2004: 333). É assim também que a constituição de diferentes repertórios terminológicos pode ser explicada. Tal posicionamento está em consonância com as últimas 
proposições de Alain Rey sobre a pluralidade e feição das terminologias pertencentes a classes terminológicas distintas (Rey, 2007).

As terminologias, portanto, não constituem um bloco monolítico, já que nem todo o processo comunicativo resume-se a expressar produção de conhecimento científico ou técnico, podendo estar orientado para privilegiar a funcionalidade necessária de atividades pragmáticas voltadas a usuários específicos. Tal situação cobra sentido no plano das informações terminológicas veiculadas pelos órgãos públicos do país.

$\mathrm{O}$ interesse em reconhecer a existência das terminologias de caráter técnico-administrativo e de procurar descrever seus princípios constitutivos, explica-se ainda pelo fato de que a Terminologia atual tem privilegiado o estudo de domínios estabelecidos do conhecimento, em particular, daqueles de feição científica, junto àqueles campos socialmente delineados como o Direito, a Economia, a Informática e o Meio Ambiente. Diferentemente, intenta-se agora identificar uma terminologia in vivo que circula socialmente e expressa uma necessidade da sociedade brasileira e uma ação pragmática de gestão pública. Trata-se de uma categoria terminológica que se pode denominar, genericamente, de terminologia técnico-administrativa, como se pretende caracterizar, tomando por base glossários produzidos por órgãos governamentais do Brasil.

O surgimento dessa categoria terminológica pode também ser compreendido à luz do pensamento de Luis Fernando Lara, em seu artigo "Término y cultura: hacia uma teoria del término" para quem nas teorias sobre termos: "ciência e cultura, particularidade e universalidade, signo e conceito não são conceitos antagônicos. O que necessita é situá-los adequadamente numa compreensão integral da significação" (Lara, 1999: 58).

\section{Terminologia técnico-administrativa}

A divulgação da informação pela rede web, certamente, é uma das maiores características da sociedade atual. Hoje, uma busca sistemática por léxicos terminológicos e glossários, orientada por critérios qualitativos, revela a existência no Brasil de uma nova realidade sociocultural, no sentido de que grande número de órgãos públicos está sistematizando e divulgando suas terminologias ${ }^{2}$.

2 Esta observação é decorrente de resultados obtidos por projeto de pesquisa, desenvolvido junto ao PPG de Linguística Aplicada da UNISINOS. Com o estabelecimento de 
Apesar de o Brasil não se caracterizar por adotar estratégias linguísticas no âmbito de suas políticas públicas, tem chamado atenção a mudança de rumos no campo da comunicação, tendo em vista a divulgação das terminologias e dos respectivos conceitos empregados em vários de seus órgãos administrativos. A colocação em prática de uma terminologia a ser compartilhada favorece uma produtiva interação que agiliza os processos comunicacionais e, como tal, qualifica a informação sobre a prestação de serviços por parte do Estado.

Nas páginas web de ministérios, secretarias e, sobretudo, de agências reguladoras, as quais integram a administração indireta, encontram-se glossários com os termos e os respectivos conceitos adotados nessas instâncias. Trata-se de um quadro ainda incipiente, mas que permite constatar que há uma terminologia "oficial" do Brasil, mesmo que divulgada pontual e fragmentadamente. São exemplos dessas situações, os glossários dos Ministérios da Saúde e da Fazenda, além dos das agências reguladoras como a Agência Nacional de Vigilância Sanitária (ANVISA), a Agência Nacional do Petróleo, Gás Natural e Biocombustíveis (ANP) e a Agência Nacional de Energia Elétrica (ANEEL), do Banco Central, entre outros.

As práticas terminológicas construídas pela administração pública constituem uma realidade linguística que motiva o interesse sobre esse léxico especializado. A aproximação a esses repertórios léxicos, como aqui se intenta fazer, não visa uma análise crítica valorativa desses repertórios, mas tão somente descrever suas formas de constituição, ainda a descoberto. Para tanto, toma-se, por base, o princípio de que a constituição de uma terminologia está vinculada aos propósitos da comunicação especializada (Krieger, 2004) que, por sua vez, reflete e constitui a dimensão cognitiva das áreas de conhecimento especializado. A isso, somam-se, dependendo da natureza da área, instrumentos operacionais necessários à prática profissional em questão. Em tal perspectiva, que relaciona texto e léxico especializado, a constituição de uma terminologia está vinculada à arquitetura cognitiva da área e à funcionalidade pragmática a que se propõe. Este último aspecto é inerente à natureza de áreas com fins aplicados, como já mencionado.

À luz dessas considerações, passamos então a examinar alguns repertórios terminológicos de órgãos da administração pública para identificar suas especificidades. É bem verdade que o termo administração pode ser

determinados filtros de qualidade, identificamos um significativo número de glossários disponíveis na internet por órgãos públicos. Tais glossários têm subsidiado um estudo sobre categorias terminológicas. 
empregado em dois sentidos: o de gestão ou management, como é frequentemente empregado, e o de "o conjunto de organismos públicos encarregados de conduzir e executar as tarefas públicas destinadas a atender o interesse coletivo", conforme Alcaraz Varó e Hughes (2002: 312).

Neste momento, bem entendido, faz-se referência aos órgãos administrativos, importando considerar suas missões de modo a descrever a constituição da terminologia que praticam e divulgam. No caso dos ministérios, segundo site do governo federal, ações da seguinte natureza definem suas principais competências:

Os Ministérios elaboram normas, acompanham e avaliam os programas federais, formulam e implementam as políticas para os setores que representam. São encarregados, ainda, de estabelecer estratégias, diretrizes e prioridades na aplicação dos recursos públicos. Os ministros auxiliam o Presidente da República no exercício do Poder Executivo. O de Relações Exteriores, por exemplo, assessora na formulação e execução da política externa brasileira (http://www.brasil.gov.br/governo_federal/estrutura/ministerios)

A título ilustrativo de que as terminologias integrantes dos glossários dos órgãos públicos têm características híbridas, considerando que expressam conceitos básicos de seus campos de atuação, cobrem suas finalidades, suas determinações normativas e mecanismos necessários à operacionalização de seus propósitos, recorremos ao Ministério da Fazenda, cuja caracterização está assim expressa em sua página web.

O Ministério da Fazenda é o órgão que na estrutura administrativa da República Federativa do Brasil cuida basicamente da formulação e execução da política econômica

(http://www.fazenda.gov.br/portugues/institucional/oquee.asp).

Ilustram essa competência, termos e respectivos conceitos próprios da gestão econômica do país, conforme se lê em:

\section{Politica Fiscal}

Coordenação da tributação, divida pública e despesas governamentais, com o objetivo de promover o desenvolvimento e a estabilização da economia. Opera, basicamente, através de três esquemas: via tributo sobre a renda e produção, via incentivos e abatimentos fiscais.

Como se observa, o termo acima estabelece e define a competência principal do Ministério da Fazenda: a política econômica, cuja natureza é fundamentada na política fiscal. Essa mesma razão justifica a presença de termos como tributo e lei de meios, a seguir reproduzidos: 


\section{Tributo}

Receita instituida pela União, pelos Estados, Distrito Federal e Municípios, compreendendo os impostos, as taxas e contribuicões de melhoria, nos termos da Constituição e das leis vigentes em matéria financeira. A Constituição de 1988 colocou as contribuiçoes sob o mesmo regime constitucional dos tributos em geral, às quais são aplicadas as normas gerais de legislação tributária e os princípios da legalidade, irretroatividade e anterioridade.

\section{Lei de Meios}

Sinônimo de Lei Orçamentária ou Lei de Orçamento. Assim denominada porque possibilita os meios para o desenvolvimento das ações relativas aos diversos órgãos e entidades que integram a administração pública.

\section{Ad valorem}

Traducão = "conforme o valor". Um tributo "ad valorem" é aquele cuja base de cálculo é o valor do bem tributado. Contrasta com o tributo especifico, arrecadado conforme uma dada quantia.

Esses quatro primeiros termos selecionados bem expressam as bases cognitivas da atuação do Ministério da Fazenda, envolvendo propósitos, conceitos e mecanismos operacionais, além de fundamentos legais. As definições apresentadas traduzem, portanto, o alcance e o modo de atuação do órgão, evidenciando que os termos efetivamente estão circunscritos à atuação do Ministério e, à exceção de ad valorem, as denominações valem-se do léxico geral.

Em paralelo, integram o mesmo glossário, unidades terminológicas que estabelecem princípios chaves para o funcionamento do órgão a exemplo de anualidade do orcamento e data base:

\section{Anualidade do Orçamento}

Princípio orçamentário que estabelece a periodicidade de um ano para as estimativas da receita e fixação da despesa, podendo coincidir ou não com o ano civil.

\section{Data Base}

Data inicial, estabelecida no contrato, para cálculo da variação do indice de custos ou preços.

De algum modo, esses dois últimos termos traduzem princípios operacionais que são básicos para a atuação do Ministério da Fazenda. Nessa mesma direção, o glossário contém a relação dos impostos a serem pagos 
pelo contribuinte, que são os mecanismos formais de sua atuação, como o próprio imposto de renda (IR) e o imposto sobre operações financeiras (IOF), este assim definido: "É tributo que compete à União, nos termos da Constituição. A Secretaria da Receita Federal é o órgão com atribuições para prestar esclarecimentos sobre os tributos federais."

Nesse mesmo âmbito de atuação, alinham-se autorizaçãa e incentivo fiscal:

\section{Autorização}

Consentimento dado ao administrador para realizar determinada operação de receita ou de despesa pública.

\section{Incentivo Fiscal}

Assume, geralmente, a forma de isenção parcial ou total de um imposto, tendo por objetivo, incrementar um determinado segmento produtivo, transferir recursos para o desenvolvimento de regiōes carentes ou melhorar a distribuição de renda do país.

Se os exemplos anteriores evidenciam a arquitetura cognitiva e a dimensão pragmática do Ministério da Fazenda, seu glossário inclui termos e conceitos oriundos das ciências econômicas e de órgãos que se ocupam de dados econômicos, mas que não se equivalem ao Ministério em propósitos específicos. São exemplos da diversidade de termos tomados a outros campos, unidades que expressam indicadores econômicos, como:

\section{Índice de Preços ao Consumidor (IPC)}

Índice calculado pela FIBGE entre os dias 16 de um mês e 15 do mês seguinte. Sua metodologia de cálculo é a mesma utilizada para o INPC, diferindo apenas quanto ao periodo de coleta de dados.

\section{Índice de Preços ao Consumidor FIPE (IPC-FIPE)}

Índice calculado pela USP no período compreendido entre os dias 01 e 30 de cada mês. Apura a variação dos preços para as famílias domiciliadas na regiãa de São Paulo, com rendimentos entre 01 e 05 salários minimos. Sua composição e ponderação são as seguintes: alimentação, 37,67\%; habitaģão, 18,35\%; despesas pessoais, 19,56\%; vestuário, 8,06\%; transporte, 10,54\%; saúde, 3,78\% e educacãa, 2,04\%

\section{Índice Geral de Preços (IGP)}

Índice calculado pela Fundação Getúlio Vargas nas regiões metropolitanas do Rio de Janeiro e São Paulo, no período entre o dia 12 e o último dia de cada mês. É composto pela ponderação de três outros indices, com os seguintes pesos: Índice de Preço no Atacado (IPA), 
60\%; Índice de Preşo ao Consumidor (IPC), 30\% e Índice Nacional da Construção Civil (INCC), $10 \%$.

\section{Índice Nacional de Preços ao Consumidor (INPC)}

Calculado pela FIBGE entre os dias 01 e 30 de cada mês. Compöe-se do cruzamento de dois parâmetros: a pesquisa de preşos de nove regiōes de produção econômica, cruz̨ada com a pesquisa de orçamento familiar, (POF) que abrange familias com renda de l (um) a 8 (oito) salários minimos. As regiōes e ponderaçoes são as seguintes: São Paulo, 28,46\%; Rio de Janeiro, 12,52\%; Belo Horizonte, 11,36\%; Salvador, 9,10\%; Porto Alegre, 7,83\%; Recife, 7,10\%; Brasilia, 6,92\%; Fortaleza, 5,61\%; Belém, 4,20\%.

Sob o prisma da diversidade, vale ainda referir a presença de termos como laranja e quarenta recomendacões que indicam respectivamente um item léxico vulgarizado e um outro integrante de conhecimentos específicos da área econômica, a saber:

\section{Laranja}

Pessoa que se apresenta como responsável por ato(s) ou empreendimento(s) de outrem, que não quer ou não pode aparecer; testa-de-ferro.

\section{Quarenta Recomendações}

Recomendacões elaboradas pelo Gafi que abrangem um conjunto de medidas relacionadas à prevenção da lavagem de dinheiro e que cobrem o sistema judiciário e de aplicação das leis, o sistema financeiro e sua regulamentação e a cooperação internacional.

Independentemente de algumas possíveis inadequações de registro de termos, o Glossário do Ministério da Fazenda evidencia uma categoria terminológica de caráter técnico-administrativo. Se o caráter técnico pode ser definido como o fundamento cognitivo da área, equivalendo aos conceitos necessários à operacionalização desse órgão público, suas regulamentações normativas e seus mecanismos operacionais definem-lhe o caráter administrativo. Isto porque cobrem sua competência e seus modos de atuação pragmática, configurando sua terminologia e respectivos conceitos. Através dessa terminologia fica evidente inclusive o papel prescritivo da gestão dos assuntos tributários, tendo em vista que as prescrições orientadoras do dever tributarista determinam o cumprimento de uma obrigação do cidadão.

Muito embora o viés prescritivo fique atenuado em determinados casos, a feição técnico-administrativa é recorrente nos órgãos regulamentadores 
de ações e compromissos de alcance político e social. É também elucidativo dessa realidade, a terminologia disponível pela ANVISA. Seu glossário reflete a finalidade da agência, definida pela missão de: "Proteger e promover a saúde da população garantindo a segurança sanitária de produtos e serviços e participando da construção de seu acesso" (http://e-glossario.anvisa. gov.br/glossary).

As funções e mecanismos de atuação dessa agência estão circunscritos por meio de termos, cujos conceitos expressam formas de verificação próprias do controle das condições de produtos alimentares e de medicamentos. Em síntese, a ANVISA tem por missão fiscalizar produtos disponíveis no mercado para que estes não prejudiquem a saúde humana. É nessa direção que, em seu glossário, coexistem termos como responsável técnico, autoridade sanitária, apreensão, registro de medicamento, agentes da vigilância, bem como dispositivos normativos e legais de ação como análise de controle, análise fiscal, análise fiscal de alimentos, conforme se lê:

\section{Análise de controle}

A efetuada em produtos sob o regime de vigilancia sanitária, após sua entrega ao consumo e destinada a comprovar a conformidade do produto com a fórmula que deu origem ao registro.

\section{Análise fiscal}

Análise efetuada sobre os produtos submetidos ao sistema instituido por este Regulamento, em caráter de rotina, para apuração de infração ou verificação de ocorrência de desvio quanto à qualidade, segurança e eficácia dos produtos ou matérias-primas.

\section{Análise fiscal de alimentos}

A efetuada sobre o alimento apreendido pela autoridade fiscalizadora competente e que servirá para verificar a sua conformidade com os dispositivos deste decreto-lei e de seus Regulamentos.

Ao mesmo tempo, aparecem inúmeros termos, cujos conteúdos expressam objetos de avaliação a exemplo dos diferentes tipos de água, como se pode constatar:

\section{Água natural}

Agua obtida diretamente de fontes naturais ou artificialmente captadas, de origem subterrânea, caracteriżada pelo contenido definido e constante de sais minerais (composição iônica), e pela presença de oligoelementos e outros constituintes, mas em niveis inferiores aos minimos estabelecidos para água mineral natural. 


\section{Água mineral natural}

Agua obtida diretamente de fontes naturais ou artificialmente captadas, de origem subterrânea, caracterizada pelo conteúdo definido e constante de sais minerais (composição iônica) e pela presença de oligoelementos e outros constituintes.

\section{Água potável}

Agua para consumo bumano cujos parâmetros microbiológicos, físicos, químicos e radioativos atendam ao padrão de potabilidade e que não ofereşa riscos à saúde.

\section{Água adicionada de sais}

É a água para consumo bumano preparada e envasada, contendo pelo menos um dos seguintes sais, de grau alimentício: bicarbonato de cálcio, bicarbonato de magnésio, bicarbonato de potássio, bicarbonato de sódio, carbonato de cálcio, carbonato de magnésio, carbonato de potássio, carbonato de sódio, cloreto de cálcio, cloreto de magnésio, cloreto de potássio, cloreto de sódio, sulfato de cálcio, sulfato de magnésio, sulfato de potássio, sulfato de sódio, citrato de cálcio, citrato de magnésio, citrato de potássio e citrato de sódio. Não deve conter açucares, adoçantes, aromas ou outros ingredientes.

A caracterização desses quatro tipos de água revela também que os conceitos a eles correlacionados evidenciam conhecimentos científicos da área da química e que não sofrem transformação semântica ao serem transladados ao universo de fiscalização da ANVISA. Dessa forma, o hibridismo de seu glossário também se reafirma, conjugando termos e conceitos próprios, estabelecidos de acordo com seus propósitos e mecanismos de atuação, junto a alguns conceitos oriundos de áreas científicas que corroboram o conhecimento e o fazer da agência. No entanto, é a prevalência dos termos e conceitos necessários à comunicação especializada da ANVISA que confere à sua terminologia o caráter técnico-administrativo, que se intenta aqui salientar.

Ao modo de confirmação do hibridismo que caracteriza a terminologia de órgãos e entidades com competência administrativa, independentemente de suas esferas de atuação, toma-se o Glossário da ANP, que, segundo sua página web foi: “implantada há dez anos pelo Decreto no 2.455, de 14 de janeiro de 1998, é o órgão regulador das atividades que integram a indústria do petróleo e gás natural e a dos biocombustíveis no Brasil" (http:// www.anp.gov.br/?id=262).

Nesse glossário, coexistem termos que cobrem desde suas normas de operacionalização até aspectos comerciais e fundamentos científicos. São exemplos de bases de operacionalização termos como calibração e sistema de produção, reproduzidos a seguir: 


\section{Calibração}

Conjunto de operações que estabelece, sob condições especificadas, a relação entre os valores indicados por um instrumento de medição ou pelo próprio sistema de medição ou valores representados por uma medida materializada ou um material de referência, e os valores correspondentes das grandezas estabelecidos por padrões.

\section{Sistema de Produção}

Conjunto de instalações destinadas a promover a coleta, a separação, tratamento, estocagem e escoamento dos fluidos produridos e movimentados em um campo de petróleo ou gás natural. RESOLUÇAOAO ANP Nº 27, DE 18.10.2006

Por sua vez, conceitos científicos tomados a áreas como a química estão representados por determinados itens, tais como butano e caloria, além de aspectos comerciais, expressos por termos como royalties e revendedor vinculado, sendo este último assim conceituado: "Revendedor autorizado pela ANP a comercializar combustiveis de aviação, que guarde vínculo comercial com um único distribuidor do qual ostente sua marca comercial. RESOLUÇÃO ANP N 18, DE 26.7.2006".

Muitos outros exemplos poderiam aqui ser arrolados com as mesmas características técnico-administrativas, como os glossários divulgados pela Petrobrás e pelo Banco Central do Brasil. No entanto, menos que quantidade, importa caracterizar a terminologia de gestão pública em seu hibridismo, o qual é dependente da competência do órgão, o que envolve a arquitetura cognitiva da esfera de atuação, os mecanismos de operacionalização das missões de cada instância administrativa, bem como dos conceitos científicos que dão suporte à execução do fazer específico em pauta. Essa inter-relação responde pela constituição das terminologias de caráter técnico-administrativo, marcadamente dos órgãos responsáveis pela gestão pública do Brasil.

\section{Breve reflexão final}

A tentativa de identificar, mesmo em grandes linhas, as características do léxico especializado disponível nas instâncias públicas do Brasil, pretendeu contribuir para a reflexão sobre a natureza e a constituição dos repertórios terminológicos, abarcando um ângulo - a gestão pública - que se estende para além do quadro socialmente reconhecido das atividades profissionais. Entende-se que se encontra aí uma categoria de termos, de caráter técnicoadministrativo, que se soma aos campos essencialmente científicos, jurídicos, 
técnicos e tecnológicos. Com essa categoria, se reconhece também que o Brasil está delineando uma terminologia "oficial", mesmo que ainda de forma parcial.

Indissociável à constatação de que essa categoria terminológica é marcada pelo hibridismo, impõe-se uma breve reflexão sobre a natureza constitutiva das unidades terminológicas que compõem repertórios híbridos a iniciar pelo fato de que multidisciplinaridade e hibridismo são configurações que não se recobrem obrigatoriamente. Se o componente multidisciplinar está associado à conjunção de vozes de áreas de competências distintas para equacionar um campo de conhecimento, a exemplo da Ecologia, que se vale de conceitos de inúmeras ciências da natureza para estabelecer o saber científico sobre o meio ambiente, o hibridismo, como aqui referido, não se equaciona do mesmo modo. Em princípio, a formação híbrida de um repertório terminológico decorre dos diferentes ângulos que constituem um saber e sua prática. De tal forma, as terminologias das instâncias administrativas traduzem a finalidade de cada órgão, o alcance e seu modo de atuação, além de seus conceitos basilares.

O conjunto dos itens léxicos, ao dimensionar o papel de cada setor da administração pública, seus conceitos e mecanismos operacionais, desenha a arquitetura cognitiva e funcional do domínio de competência. Em decorrência, cabe redefinir os termos para além da tradição que costuma compreendê-los somente como nódulos cognitivos, mas também como representação dos mecanismos operacionais dos fazeres profissionais. Dito de outro modo: “o 'objeto' desses processos, nos quais o significado terminológico está consolidado, é a totalidade das 'coisas' e 'fatos' que devem ser aprendidos" (Rey, 2007: 334).

Entretanto, é preciso ainda lembrar que aos contextos híbridos pode agregar-se algum termo que expressa um conceito oriundo de outra área, requisitado como um suporte necessário para dimensionar um campo de saber. Nesses casos, os termos mantêm seus sentidos originais sem reinscrição conceitual. Quando tal fato ocorre, o termo "naturaliza-se" dentro de cada quadro terminológico específico em razão do ponto de vista de cada área. De forma concreta, pode-se observar a presença de um mesmo termo em dois glossários distintos da administração pública, mas circunscritos a especificidades de cada órgão. Trata-se de petróleo brent, termo definido pela ANP e pelo Banco Central, cujos conceitos a ele relacionados ficam melhor explicados, examinando-se antes o significado primeiro de brent no glossário da Petrobrás: 
Brent-Mistura de petróleos produzidos no Mar do Norte, oriundos dos sistemas petroliferos Brent e Ninian, com grau API de 39,4 e teor de enxofre de 0,34\%.

\section{Petróleo Brent}

Mistura de tipos de petróleo produzidos no Mar do Norte, oriundos dos sistemas petroliferos Brent e Ninian.

\section{Petróleo Brent}

Barril de petróleo negociado no mercado de Londres (LIPE).

Estas breves reflexões retomam vários aspectos de questões básicas, e mesmo iniciais, da Terminologia. Não obstante, é preciso ainda dar continuidade a estudos descritivos, posto que podem contribuir para um conhecimento mais profundo dos padrões e perfis constitutivos dos repertórios terminológicos. Pesquisas que descrevem os padrões e particularidades da terminologia de uma determinada área e que estabeleçam comparações entre as distintas categorias de léxico especializado trazem em seu bojo duas implicações maiores:

a) uma contribuição teórica acerca do modo de constituição dos léxicos especializados;

b) um valor metodológico, no sentido de orientar o reconhecimento da terminologia de áreas de práticas e conhecimentos especializados, que ainda não tiveram seus termos repertoriados.

Esse último aspecto relaciona-se diretamente a uma das grandes problemáticas da terminografia, bem como de outros tipos de estudos e atividades que envolvem o manejo de terminologias, qual seja a condição de um candidato a termo e o reconhecimento de seu efetivo estatuto de termo. Todos os componentes envolvidos nesse reconhecimento dimensionam a multidiversidade de fatores - cognitivos, pragmáticos, comunicacionais, discursivos, sociais e culturais - a que a Terminologia está afeta. Dimensionase também o alcance das reflexões relacionadas aos léxicos especializados.

Referências bibliográficas

ALCARAZ VARÓ, E.; HUGHES, B. 2002. El español jurídico. Barcelona: Ariel.

BRASIL. Banco Central do Brasil. Glossário [do]. Brasília, DF: Disponível em: <http:// www.bcb.gov.br/?GLOSSARIO>. Acesso em 12 nov. 2009. 
BRASIL. Ministério de Minas e Energia. Glossário ANP. Brasília, DF: Agência Nacional do Petróleo, Gás Natural e Biocombustíveis. Disponível em: < http://www.anp.gov.br/glossario/ index.asp>. Acesso em 25 set. 2009.

BRASIL. Ministério da Fazenda. Glossário [do]. Brasília, DF: Disponível em: <http://www. tesouro.fazenda.gov.br/servicos/glossario/glossario_a.asp>. Acesso em 25 set. 2009.

BRASIL. Ministério da Saúde. Glossário de Vigilância Sanitária. Brasília, DF: Agência Nacional de Vigilância Sanitária. Disponível em: <http://e-glossario.anvisa.gov.br>. Acesso em 14 out. 2009.

BRASIL. Petrobras. Glossário [da]. Brasília, DF: Disponível em: <http://www2.petrobras. com.br/ri/port/glossario/glossario.asp\#b>. Acesso em 12 nov. 2009.

KRIEGER, M. G., 2009. Terminologia técnico-científica em espaço público: que terminologia é essa? Revista da ANPOLL. 26. (no prelo).

LARA, F. L. 1999. Término y cultura: hacia una teoría del término. In: CABRÉ, M.T.; LORENTE, M. Terminologia y modelos culturales. Barcelona: IULA/Universitat Pompeu Fabra.

REY, A. 2007. A terminologia entre a experiência da realidade e o comando dos signos. In: ISQUERDO, A.N.; ALVES, I. M. As ciências do léxico. v. 3. Campo Grande: UFMS.

WÜSTER, E. 1996. La teoria general de la terminologia: una zona fronterera entre la lingüística, la lògica, l’ontologia, la informàtica i les ciències especialitzades. In: CABRÉ, M. T. Terminologia. Selecció de textos d'E. Wüster. Barcelona: Servei de Llengua Catalana de la Universitat de Barcelona. p. 153-202.

1998. Introducción a la teoría general de la terminología y a la lexicografía terminológica. Barcelona: IULA/Universitat Pompeu Fabra. (Sèrie monografies, n. 1). 